\title{
Sex-specific microRNA expression networks in an acute mouse model of ozone-induced lung inflammation
}

\author{
Nathalie Fuentes ${ }^{1}$, Arpan Roy ${ }^{2}$, Vikas Mishra ${ }^{1}$, Noe Cabello ${ }^{1}$ and Patricia Silveyra ${ }^{1,3^{*}}$ (D)
}

\begin{abstract}
Background: Sex differences in the incidence and prognosis of respiratory diseases have been reported. Studies have shown that women are at increased risk of adverse health outcomes from air pollution than men, but sex-specific immune gene expression patterns and regulatory networks have not been well studied in the lung. MicroRNAs (miRNAs) are environmentally sensitive posttranscriptional regulators of gene expression that may mediate the damaging effects of inhaled pollutants in the lung, by altering the expression of innate immunity molecules.

Methods: Male and female mice of the C57BL/6 background were exposed to $2 \mathrm{ppm}$ of ozone or filtered air (control) for $3 \mathrm{~h}$. Female mice were also exposed at different stages of the estrous cycle. Following exposure, lungs were harvested and total RNA was extracted. We used PCR arrays to study sex differences in the expression of 84 miRNAs predicted to target inflammatory and immune genes.

Results: We identified differentially expressed miRNA signatures in the lungs of male vs. female exposed to ozone. In silico pathway analyses identified sex-specific biological networks affected by exposure to ozone that ranged from direct predicted gene targeting to complex interactions with multiple intermediates. We also identified differences in miRNA expression and predicted regulatory networks in females exposed to ozone at different estrous cycle stages.

Conclusion: Our results indicate that both sex and hormonal status can influence lung miRNA expression in response to ozone exposure, indicating that sex-specific miRNA regulation of inflammatory gene expression could mediate differential pollution-induced health outcomes in men and women.
\end{abstract}

Keywords: Lung miRNome, Estrous cycle, Air pollution, miR-712-5p, miR-106a-5p

\section{Background}

Ground-level ozone $\left(\mathrm{O}_{3}\right)$ is a reactive oxidant gas that is a major constituent of air pollution [1]. Ozone is formed by the photochemical reactions of carbon monoxide, nitrogen oxides, and chemically active hydrocarbons also known as volatile organic compounds and mostly occurs downwind of major cities. The association of short-term ambient exposure of $\mathrm{O}_{3}$ with the incidence of respiratory afflictions such as asthma, idiopathic pulmonary fibrosis, and chronic obstructive pulmonary disease (COPD), as

\footnotetext{
* Correspondence: pzs13@psu.edu

${ }^{1}$ Pulmonary, Immunology and Physiology Laboratory, Department of Pediatrics, The Pennsylvania State University College of Medicine, 500 University Drive, H085, Hershey, PA 17033, USA

${ }^{3}$ Department of Biochemistry and Molecular Biology, The Pennsylvania State University College of Medicine, Hershey, PA, USA

Full list of author information is available at the end of the article
}

well as cardiovascular mortality indicates that $\mathrm{O}_{3}$ is a powerful toxicant for the cardiorespiratory system [2-6]. In addition, epidemiological studies have reported sex differences in the incidence and prognosis of pollutioninduced respiratory diseases and have shown that women are at increased risk of adverse health outcomes from $\mathrm{O}_{3}$, particulate matter, and cigarette smoke exposure than men [7-10].

Being a gaseous pollutant, the primary effect of $\mathrm{O}_{3}$ occurs in the lung causing a range of respiratory ailments [11-13]. The mechanisms by which $\mathrm{O}_{3}$ mediates these effects involve generation of reactive oxygen species (ROS) triggering oxidative stress [14]. In addition, proinflammatory cytokines have been implicated as potential mediators of lung oxidative injury in response to air pollution exposure [15]. Among these cytokines,

(C) The Author(s). 2018 Open Access This article is distributed under the terms of the Creative Commons Attribution 4.0 International License (http://creativecommons.org/licenses/by/4.0/), which permits unrestricted use, distribution, and 
interleukin-6 (IL-6) contributes to the initiation and extent of the inflammatory process [16]. In a previous study, we have demonstrated that expression of IL-6 in the lung is significantly induced by $\mathrm{O}_{3}$ inhalation in both males and females, with significantly higher levels in females vs. males [17]. However, to this day, the molecular mechanisms involved in the observed sex differences remain unknown.

In the last couple of decades, a novel posttranscriptional gene regulation machinery has been identified with the discovery of short (19-25 nucleotides), naturally occurring, non-coding RNA molecules, known as microRNAs (miRNAs). This class of small RNA molecules is evolutionarily conserved and functions in the fine-tuning of gene expression by direct translational inhibition and/or induction of target mRNA degradation [18]. It has also been reported that miRNAs can be oxidized in response to oxidative stress, via guanine hydroxylation, altering their ability to bind to target mRNA sequences [19]. In addition, miRNAs are involved in various important biological processes such as the immune response, cell differentiation, developmental processes, and apoptosis [20, 21]. In the lung, miRNAs play important roles in developmental processes and in homeostasis maintenance, and their abnormal expression has been associated with the development and progression of various pulmonary diseases [22-25].

The role of miRNAs in lung development was first elucidated in mice, where conditional deletion of Dicer (an important enzyme of the miRNA synthesis pathway) in lung epithelial cells resulted in impaired epithelial branching and developmental abnormalities and also led to dysregulated cell death [26]. In addition, abnormal expression of miRNAs has been correlated with the occurrence of pulmonary disorders such as asthma, COPD, and lung cancer in both children and adults [27-31]. Despite the known sex disparities in the incidence and severity of these diseases [32, 33], there are currently very few studies exploring the role of miRNAs in mediating these sex-biased disease outcomes [34].

We have previously reported sex differences in the expression of lung inflammatory markers in response to $\mathrm{O}_{3}$, and we have shown that pre-exposure to this air pollutant affected lung immunity in a sex-specific manner [35-37]. Additional studies revealed a potential role of gonadal hormones in this regulation [38]. However, the molecular mechanisms by which the male and female lungs respond to ambient $\mathrm{O}_{3}$, and the specific role of miRNAs in this regulation, have not yet been explored. Based on these preliminary data, we hypothesized that sex-specific miRNA expression can mediate gender-specific immune responses to $\mathrm{O}_{3}$ via modulation of pulmonary inflammatory gene expression. Thus, the goal of this study was to determine whether sex and hormonal status could modulate lung miRNA expression networks during $\mathrm{O}_{3}$-induced acute inflammation. For this, we compared the expression of specific miRNAs in the lungs of male and female mice exposed to $\mathrm{O}_{3}$ or filtered air (FA, control), and we used bioinformatics approaches to compare predicted regulatory networks and target genes associated with innate immunity and inflammation. With the goal of evaluating potential contributions of female sex hormones to these networks, we also evaluated differences in the lung miRNA expression of female mice exposed to $\mathrm{O}_{3}$ or FA at different stages of the estrous cycle. Our results indicate that $\mathrm{O}_{3}$ exposure differentially affects lung miRNA expression in male and female mice and that the stage of the estrous cycle does affect the miRNA expression signature. We also identified miRNAs that have been previously associated with IL- 6 regulation and that were differentially expressed in females and males in response to $\mathrm{O}_{3}$ challenge $[39,40]$. To our knowledge, this is the first study investigating both inflammatory miRNA networks and hormonal influences in response to $\mathrm{O}_{3}$ exposure. This information can have significant implications for environmental and women's health and the development of novel therapeutics to treat and prevent lung disease in women.

\section{Methods \\ Animals}

Adult male and female mice ( 8 weeks of age) from the C57BL/6 background were purchased from JAX laboratories (Bar Harbor, ME) and housed and maintained in a 12/12-h light/dark cycle with food and water available ad libitum. The Pennsylvania State University College of Medicine Institutional Animal Care and Use Committee (IACUC) approved all procedures (protocol \#42135). The institution is accredited by the Association for Assessment and Accreditation of Laboratory Animal Care (AAALAC).

\section{Assessment of estrous cycle stage}

We determined estrous cycle stage in female mice by analysis of daily vaginal secretions for at least three consecutive cycles, as described previously [41]. For this, a smear of vaginal flush was prepared and observed under light microscope. Based on the smear appearance, the estrous cycle stage was determined by the proportion of nucleated epithelial cells, leukocytes, and cornified cells, as follows: proestrus (predominantly nucleated epithelial cells), estrus (predominantly anucleated cornified cells), diestrus $1 /$ metestrus (all three types of cells), and diestrus 2 (majority of leukocytes). Animals that did not show regular cycles due to pseudopregnancy or other causes were excluded from the experiment.

\section{Exposure to $\mathrm{O}_{3}$}

Male mice and female mice at different stages of the estrous cycle ( $n=3-9$ animals per group) were placed in 
glass containers with wire mesh lids containing bedding, food, and water ad libitum. Nest packs were also provided to the experimental animals to provide enrichment material to promote normal behavior and limit the extent of stress and fighting. On the day of the experiment, mice were exposed to $2 \mathrm{ppm}$ of $\mathrm{O}_{3}$ for $3 \mathrm{~h}$, using an exposure chamber $(2.089 \pm 0.021 \mathrm{ppm})$. [42]. Control animals were exposed to filtered air (FA) for $3 \mathrm{~h}$ in an adjacent chamber. The apparatus delivers a regulated air flow ( $>30$ air changes/hour) with controlled temperature $\left(25{ }^{\circ} \mathrm{C}\right)$ and relative humidity (50\%). Following exposure, animals were removed from the apparatus, and samples were collected as described below. At $4 \mathrm{~h}$ after exposure, animals were anesthetized with an intraperitoneal injection of a ketamine/xylazine cocktail $(90 \mathrm{mg} / \mathrm{kg}$ ketamine, $10 \mathrm{mg} / \mathrm{kg}$ xylazine). A midline incision was made, and blood was collected by aspiration from the inferior vena cava. Mice were then euthanized by transection of the vena cava and aorta. Total lung tissue was collected and snap frozen in liquid nitrogen for miRNA expression experiments. To control for any circadian variations and to be able to monitor evening hormone peaks associated with estrous cycle stages, we exposed all animals at the same time of the day (11:00 am-2:00 pm) regardless of cycle day. The lungs and blood were harvested at 6 : $00 \mathrm{pm}$. The concentration of $\mathrm{O}_{3}$ used in this study is higher than that normally found in the atmosphere. The rationale for using this concentration is that higher doses are required for rodents vs. humans to reach comparable $\mathrm{O}_{3}$ concentrations in the distal lung [43] and that rodents acutely exposed to $2 \mathrm{ppm}$ of $\mathrm{O}_{3}$ show comparable or lower levels of inflammatory markers than exercising humans exposed to much lower concentrations (0.4 ppm) [44].

\section{Serum hormone determinations}

To verify the estrous cycle stage in females, serum levels of estradiol and luteinizing hormone were determined by ELISA (cats. \#MBS9424676 and \#MBS041300, MyBioSource, San Diego, CA).

\section{RNA preparation}

Total RNA was extracted from pulverized tissue using Trizol and the Direct-Zol RNA extraction kit (Zymo Research), following the manufacturer's instructions. Total RNA concentration was measured by Nanodrop, and RNA quality was confirmed by Bioanalyzer as indicated by RIN $>7$ at the Pennsylvania State University College of Medicine Genome Sciences Core Facility.

\section{miRNA profiling}

Small RNAs were retro-transcribed from $200 \mathrm{ng}$ of total RNA using the miScript II RT kit (Qiagen). The expression of 84 mouse miRNAs predicted to regulate inflammatory genes was assayed with the Mouse Inflammatory Response and Autoimmunity miRNA PCR Array (MIMM-105Z, Qiagen). A list of miRNAs and predicted targets can be found at https://www.qiagen.com/us/shop/pcr/primer-sets/ miscript-mirna-pcr-arrays/?catno=MIMM-105Z\#geneglobe.

\section{Data analysis}

Results were analyzed using the QuantStudio 12K Flex Software, and Ct values were exported to MS excel. Data were processed following recommendations described in studies using similar samples. Briefly, data were analyzed in excel using $\mathrm{Ct}$ values for each sample, normalized to the average $\mathrm{Ct}$ of five miRNA housekeeping miRNAs controls (SNORD61, SNORD68, SNORD72, SNORD95, SNORD96A, RNU6-2) as $\Delta \mathrm{Ct}=(\mathrm{Ct}$-Target $-\mathrm{Ct}$-housekeeping). For fold change calculations, $\Delta \Delta \mathrm{Ct}$-based foldchange values were obtained using sample 27 as control, using the Livak method $\left(2^{-\Delta \Delta \mathrm{Ct}}\right.$, where $-\Delta \Delta \mathrm{Ct}=$ $-[\Delta$ Cttest $-\Delta$ Ctcontrol $])$ [45]. Arrays shown in figures are representative of fold changes calculated with this method. Statistical analyses were performed with the $\mathrm{R}$ software using the Bioconductor limma package to detect differences among treatments and correcting for multiple comparisons using the Benjamini-Hochberg method [46]. Differential expression was defined as a BenjaminiHochberg false discovery rate (FDR) of less than 0.05 .

\section{Ingenuity pathway analysis}

Significantly altered transcripts from analysis with PCR arrays were used as input for the miRNA Target Filter function in Ingenuity Pathway Analysis (IPA, Qiagen Redwood City, https://www.qiagenbioinformatics.com/products/ingenuity-pathway-analysis/) to find predicted miRNAregulated target genes differentially expressed in the lungs of males and females exposed to $\mathrm{O}_{3}$. Using the premise that reciprocal expression patterns exist between miRNA and their predicted gene targets within the defined list of differentially expressed genes, networks of predicted miRNAregulated genes were constructed to visualize the potential effects of individual miRNAs on networks. We used the IPA miRNA Target Filter function, which incorporates experimentally demonstrated and in silico predicted miRNAmRNA interactions from the databases TargetScan, TarBase, and miRecords. IPA was used to perform functional gene enrichment analysis using predicted target genes from miRNA-centered networks. Correlation of expression patterns of miRNAs and differentially expressed transcripts were performed with logarithmic fold changes and $P$ values.

\section{Results}

Sex differences in basal miRNA expression

Previous investigations have documented differences in pulmonary function parameters, innate immune responses, and lung disease pathogenesis in female and 
male mice breathing clean air. With a few exceptions, male mice are usually characterized by weaker immune responses than female mice $[47,48]$. In our model, the miRNA expression array data in lung tissue acquired from mice exposed to filtered air showed differences in miRNA expression between males and females (Additional file 1: Figure S1A). Two miRNAs, miR-222$3 p$ and miR-466 k, were differentially expressed. MicroRNA-222-3p and miR-466k were upregulated (log fold change $=0.459$ ) and downregulated (log fold change $=-0.614)$, respectively, in males vs. females (Additional file 1: Figure S1B). The in silico analysis showed a relationship between these miRNAs and major gene families such as transcription factors and protooncogenes (FOS, JUN, FOXO3, FOXP3, E2F1, CDKN2B, CCND1, ARID3B, TP53, KIT), translation regulators (AGO2), transporters (vesicle-mediated transporter CLVS2, channel/pore class transporter BCL2), nuclear receptors (ESR1, RORB), kinases (BRAF, SBK1), growth factors (BDNF), phosphatases (PTEN), and proteins in the extracellular matrix (TIMP3) (Additional file 2: Table S1). IPA analysis revealed that these molecules are associated with top molecular functions such as cell-to-cell signaling and interaction, cellular growth, proliferation, and gene expression (Additional file 3: Figure S2A).

\section{Sex differences in $\mathrm{O}_{3}$-induced lung miRNA expression}

The screening of miRNA expression in the lungs of male and female mice exposed to $\mathrm{O}_{3}$ allowed the detection of miRNAs differentially expressed between these two groups. Further analysis performed with IPA revealed that the top molecular functions associated with differentially expressed genes in males vs. females exposed to $\mathrm{O}_{3}$ were linked to cell cycle, cellular development, and cellular growth and proliferation, which are important pathways in the lung inflammatory response. Moreover, the top associated network functions included organismal and tissue development, humoral immune response, nervous system development, and reproductive system development and function. Several of these were also involved in inflammation (miR-130b-3p, miR-17-5p, miR294a-3p, and miR-338-5p) and targeted key regulators of the immune response including IL-6, SMAD2/3, and TMEM9 (Table 1, Additional file 3: Figure S2B). In total, there were nine miRNAs whose expression was significantly lower in females vs. males exposed to $\mathrm{O}_{3}$ (Fig. 1).

Differential regulatory pathways are activated in males vs. females in response to $\mathrm{O}_{3}$

Next, we analyzed sex differences in the miRNA response to $\mathrm{O}_{3}$ vs. FA exposure. Of the eight differentially expressed miRNAs found in both males and females exposed to $\mathrm{O}_{3}$, a total of six miRNAs were upregulated exclusively in males: miR-338-5p (log fold change $=1.636$ ),
Table 1 Target genes and associated regulatory networks for differentially expressed miRNAs in lung tissue of male and female mice exposed to ozone

\begin{tabular}{|c|c|c|c|c|c|}
\hline \multicolumn{6}{|c|}{ A. Genes targeted by differentially expressed miRNAs } \\
\hline $\begin{array}{l}\text { BCL2 } \\
\text { CDKN1A } \\
\text { COX8C } \\
\text { DDHD1 }\end{array}$ & $\begin{array}{l}\text { ENPP5 } \\
\text { FBXO48 } \\
\text { FGD4 } \\
\text { FICD }\end{array}$ & $\begin{array}{l}\text { GPR158 } \\
\text { GPR137C } \\
\text { IL6 } \\
\text { MARCH4 }\end{array}$ & $\begin{array}{l}\text { MBNL2 } \\
\text { MYT1L } \\
\text { PCNX1 } \\
\text { PTHLH }\end{array}$ & $\begin{array}{l}\text { RDH14 } \\
\text { RP11_65D242 } \\
\text { SLITRK3 } \\
\text { Smad2/3 }\end{array}$ & $\begin{array}{l}\text { SMAD6/7 } \\
\text { TMEM9B } \\
\text { ZNF800 }\end{array}$ \\
\hline \multicolumn{6}{|c|}{ B. Differences in top diseases and biofunctions } \\
\hline \multicolumn{4}{|c|}{ Diseases and disorders } & \multicolumn{2}{|l|}{$P$ value } \\
\hline \multicolumn{4}{|c|}{ Cancer } & \multicolumn{2}{|c|}{$4.80 \mathrm{E}-02$ to $4.62 \mathrm{E}-11$} \\
\hline \multicolumn{4}{|c|}{ Organismal injury and abnormalities } & \multicolumn{2}{|c|}{$4.80 \mathrm{E}-02$ to $4.62 \mathrm{E}-11$} \\
\hline \multicolumn{4}{|c|}{ Reproductive system disease } & \multicolumn{2}{|c|}{$4.01 \mathrm{E}-02$ to $4.62 \mathrm{E}-11$} \\
\hline \multicolumn{4}{|c|}{ Endocrine system disease } & \multicolumn{2}{|c|}{$2.28 \mathrm{E}-02$ to $3.11 \mathrm{E}-07$} \\
\hline \multicolumn{6}{|c|}{ C. Top molecular and cellular functions } \\
\hline \multicolumn{4}{|c|}{ Molecular and cellular functions } & \multicolumn{2}{|l|}{$P$ value } \\
\hline \multicolumn{4}{|c|}{ Cell cycle } & \multicolumn{2}{|c|}{$1.23 \mathrm{E}-02$ to $1.87 \mathrm{E}-05$} \\
\hline \multicolumn{4}{|c|}{ Cellular development } & \multicolumn{2}{|c|}{ 4.05E-02 to $5.81 \mathrm{E}-05$} \\
\hline \multicolumn{4}{|c|}{ Cellular growth and proliferation } & \multicolumn{2}{|c|}{$3.76 \mathrm{E}-02$ to $5.81 \mathrm{E}-05$} \\
\hline \multicolumn{6}{|c|}{ D. Top physiological system development and function } \\
\hline \multicolumn{4}{|c|}{ Development and function } & \multicolumn{2}{|l|}{$P$ value } \\
\hline \multicolumn{4}{|c|}{ Organismal development } & \multicolumn{2}{|c|}{$3.76 \mathrm{E}-02$ to $1.11 \mathrm{E}-05$} \\
\hline \multicolumn{4}{|c|}{ Tissue development } & \multicolumn{2}{|c|}{$3.76 \mathrm{E}-02$ to $7.49 \mathrm{E}-04$} \\
\hline \multicolumn{4}{|c|}{$\begin{array}{l}\text { Reproductive system development and } \\
\text { function }\end{array}$} & \multicolumn{2}{|c|}{$1.04 \mathrm{E}-02$ to $2.99 \mathrm{E}-03$} \\
\hline \multicolumn{6}{|c|}{ E. Top associated network functions } \\
\hline \multicolumn{4}{|c|}{ Associated network functions } & \multicolumn{2}{|l|}{ Score } \\
\hline \multicolumn{4}{|c|}{$\begin{array}{l}\text { Cancer, organismal injury, } \\
\text { and abnormalities }\end{array}$} & \multicolumn{2}{|l|}{27} \\
\hline
\end{tabular}

miR-222-3p (log fold change $=0.699)$, miR-130b-3p (log fold change $=0.646)$, let-7i-5p (log fold change $=0.552$ ), miR-195a-5p (log fold change $=0.543)$, and miR-144-3p (log fold change $=0.427)$ (Fig. 2). IPA analysis revealed that the top cellular functions associated with these miRNAs and their targets were cell cycle, cell death, cell survival, and cellular movement. The top interaction networks for these miRNAs were related to digestive system development and function, gastrointestinal disease, hepatic system development and function, and inflammatory disorders and response (Table 2). In females, $\mathrm{O}_{3}$ exposure induced the expression of miR301b-3p (log fold change =1.652), miR-694 (log fold change $=0.727)$, miR-669 h-3p (log fold change $=0.679)$, miR-384-5p (log fold change $=0.455)$, and miR-9-5p (log fold change $=0.378$ ) and downregulated the expression of miR-30d-5p (log fold change $=-0.204$ ) (Fig. 3). Some of these miRNAs target important regulators of the immune system such as SOCS5 and IL-10RB, which may be altering the lung host defense (Table 2). The top interaction networks in females exposed to $\mathrm{O}_{3}$ were associated with cancer, organismal injury and 

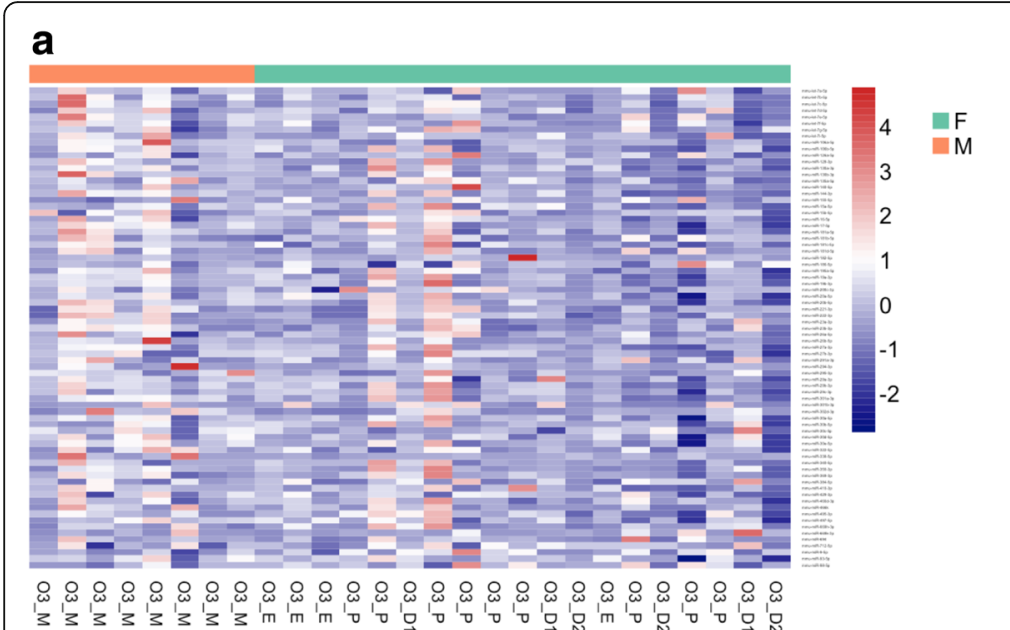

b
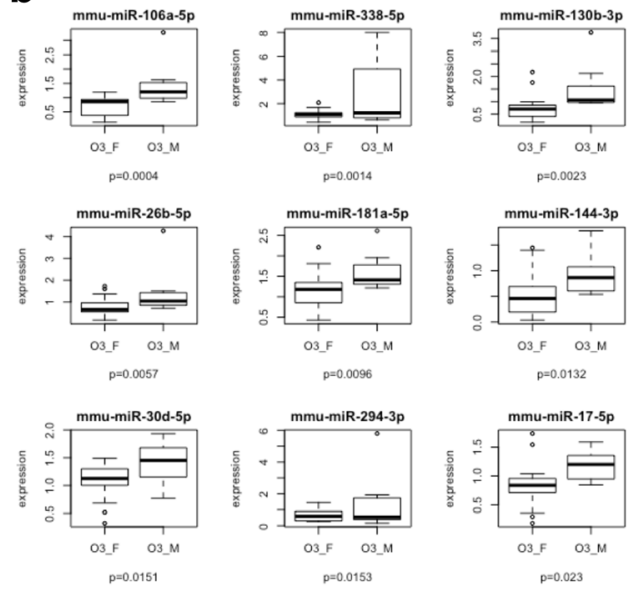

Fig. 1 Sex differences in $\mathrm{O}_{3}$-induced lung miRNA expression. a Cluster analysis of 84 miRNAs expressed in lung extracts obtained from male and female mice following exposure to 2 ppm of $\mathrm{O}_{3}$ for $3 \mathrm{~h}$. b Differentially expressed miRNAs in male and female lung extracts. Results are expressed as female miRNA expression levels relative to male miRNA expression levels. M males $(n=8)$, F females ( $n=19)$, O3_M males exposed to ozone, O3_D1 females exposed to ozone in diestrus 1, O3_D2 females exposed to ozone in diestrus 2, O3_P females exposed to ozone in proestrus, O3_E females exposed to ozone in estrus

abnormalities, and reproductive system disease. The top molecular functions affected were cellular development, cellular growth, proliferation, and cell cycle.

Interestingly, two miRNAs were affected by $\mathrm{O}_{3}$ exposure in both males and females (Fig. 4). Of these, miR712-5p was the only miRNA found upregulated in both males (log fold change $=0.658$ ) and females (log fold change $=0.543$ ). Interestingly, miR-106a-5p was upregulated in males (log fold change $=0.502$ ) but downregulated in females (log fold change $=-0.302$ ) following $\mathrm{O}_{3}$ exposure. Several genes essential for the lung inflammatory response were predicted to be targeted by these

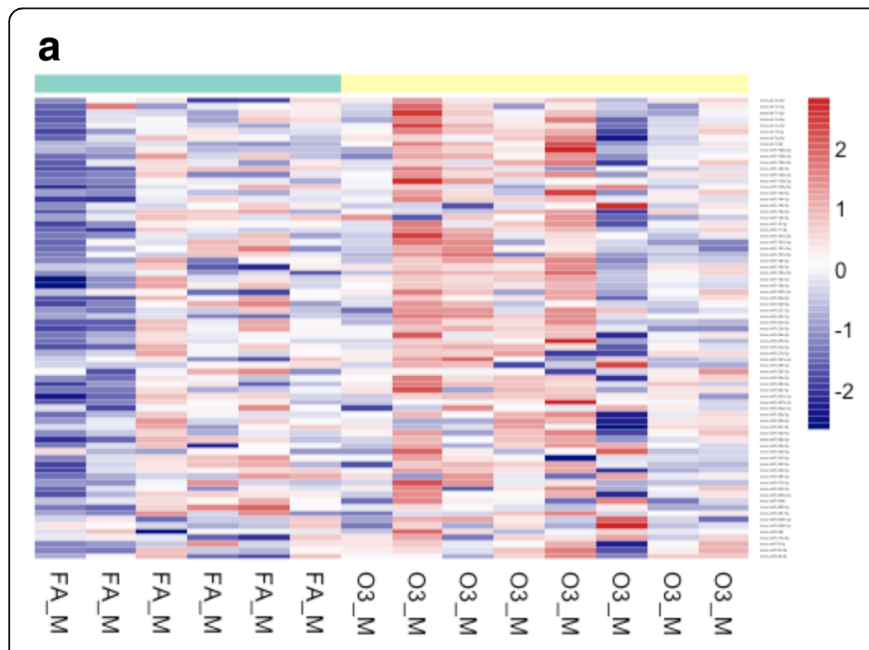

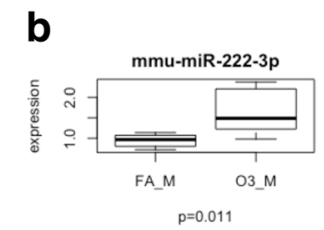
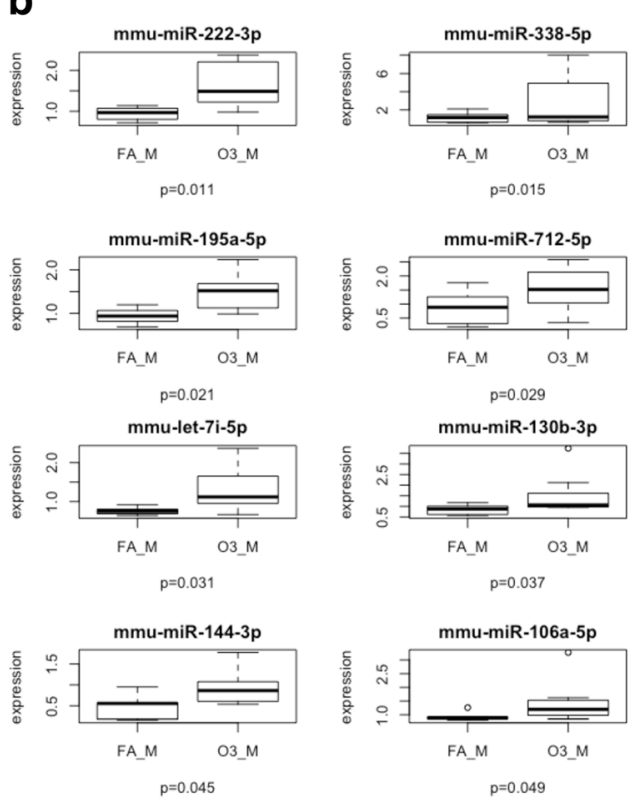

Fig. 2 Expression of lung miRNAs in males exposed to $\mathrm{O}_{3}$ vs. FA. a Cluster analysis of 84 miRNAs in lung extracts from male mice exposed to 2 ppm of $\mathrm{O}_{3}$ or FA for 3 h. $\mathbf{b}$ Differentially expressed miRNAs in males exposed to $\mathrm{O}_{3}$ vs FA. FA filtered air, O3 ozone, FA_M males exposed to filtered air $(n=6)$, O3_M males exposed to ozone $(n=8)$ 
Table 2 Summary obtained from IPA analysis of $\mathrm{FA}$ and $\mathrm{O}_{3}$ exposed male and female mice

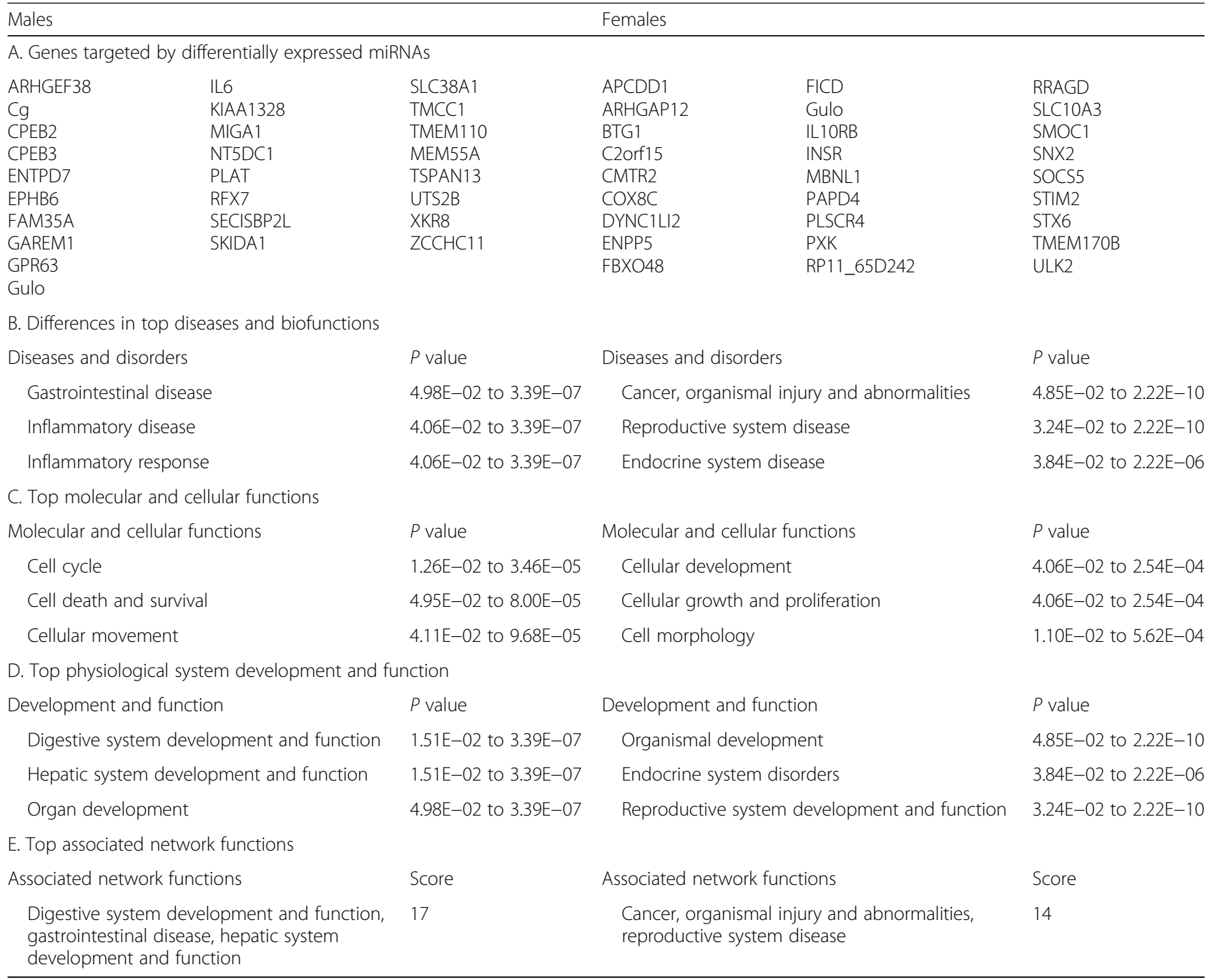

miRNAs (Tables 3 and 4). Comparison of the main pathways affected by $\mathrm{O}_{3}$ also confirmed differentially affected functions in males vs. females. Some miRNAs such as miR-338-5p, miR-106a-5p, and let-7a-5p (affected exclusively in males) were predicted to target the IL-6 family both directly and indirectly (Fig. 5).

\section{Effect of the estrous cycle stage in the miRNA response to $\mathrm{O}_{3}$ exposure}

Previous observations suggested that the negative effects of air pollution in women's lung health may be affected by sex hormones. We sought to evaluate whether fluctuations of circulating hormone levels could influence variations in the miRNA response, by exposing female mice to $\mathrm{O}_{3}$ or FA at different stages of the estrous cycle. For consistency, experiments were conducted at the same time of the day and harvest of samples was performed at 6:00 pm, to allow for the detection of preovulatory luteinizing hormone and estradiol surges in the evening of proestrus (Table 3) [49]. Our data revealed that there is an influence of the estrous cycle in the miRNA response (Fig. 6). Furthermore, comparison of miRNA expression in females exposed to $\mathrm{O}_{3}$ at the proestrus stage vs. all other stages (metestrus, diestrus, or estrus) also revealed differential signatures. Specifically, we found nine differentially expressed miRNAs in females exposed to $\mathrm{O}_{3}$ in proestrus: miR-694 (log fold change $=1.492)$, miR-9-5p (log fold change $=0.836)$, miR-712-5p (log fold change $=0$. 667), miR-181d-5p (log fold change $=0.597$ ), miR-98-5p (log fold change $=0.558)$, miR-200c-3p (log fold change $=$ 0.525), miR-221-3p (log fold change $=0.385)$, miR-126a$5 \mathrm{p}$ (log fold change $=0.421$ ), and miR-106a-5p (log fold change $=-0.527$ ) (Fig. 7). Two out of the eight upregulated miRNAs (miR-712-5p and miR-694) were not associated with any known pathways by IPA. However, according to the literature, miR-712 and miR-694 are molecules associated with key players in lung inflammation such as CCL8, IL-1RAP, IL-7, STAT5a, VEGFA, and BCL6 

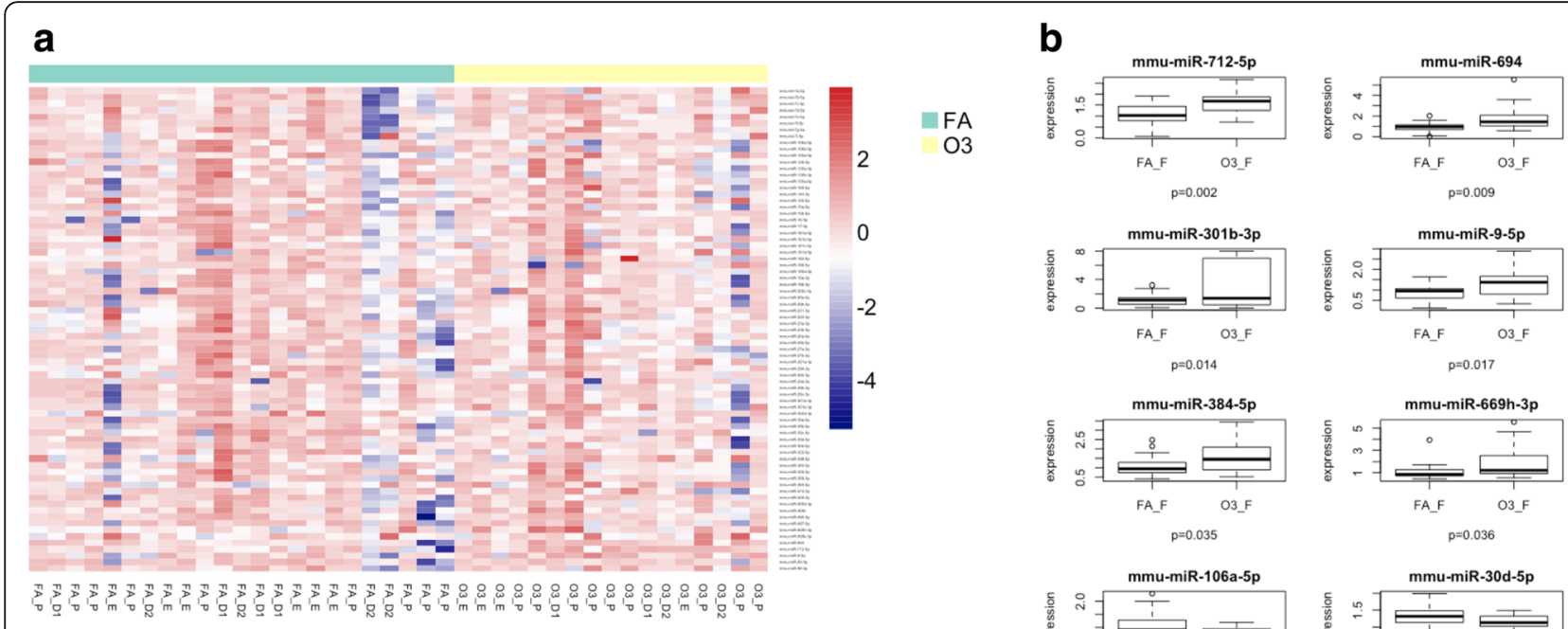

$p=0.035$
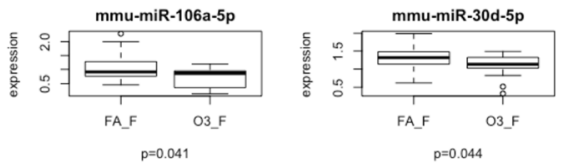

Fig. 3 Expression of lung miRNAs in females exposed to $\mathrm{O}_{3}$ vs. FA. a Cluster analysis of 84 inflammatory miRNAs in lung extracts from female mice exposed to 2 ppm of $\mathrm{O}_{3}$ or $\mathrm{FA}$ for $3 \mathrm{~h}$. $\mathbf{b}$ Differentially expressed miRNAs in females exposed to $\mathrm{O}_{3}$ vs $\mathrm{FA}$. FA filtered air ( $n=23$ ), O3 ozone $(n=19)$, FA_D1 females exposed to filtered air in diestrus 1, FA_D2 females exposed to filtered air in diestrus 2, FA_P females exposed to filtered air in proestrus, FA_E females exposed to filtered air in estrus, O3_D1 females exposed to ozone in diestrus 1, O3_D2 females exposed to ozone in diestrus 2, O3_P females exposed to ozone in proestrus, O3_E females exposed to ozone in estrus

(Table 4). Comparison of the biological networks affected by $\mathrm{O}_{3}$ in the proestrus stage by IPA confirmed differentially affected molecules when compared to the other stages of the estrous cycle. Intriguingly, key players in apoptosis (c-Myc, CASP3) and immune regulators (MITF) were present in the network (Fig. 9). The activation of cMyc and estrogen have been found to lead into the processing/activation of CASP3, which is highly expressed in

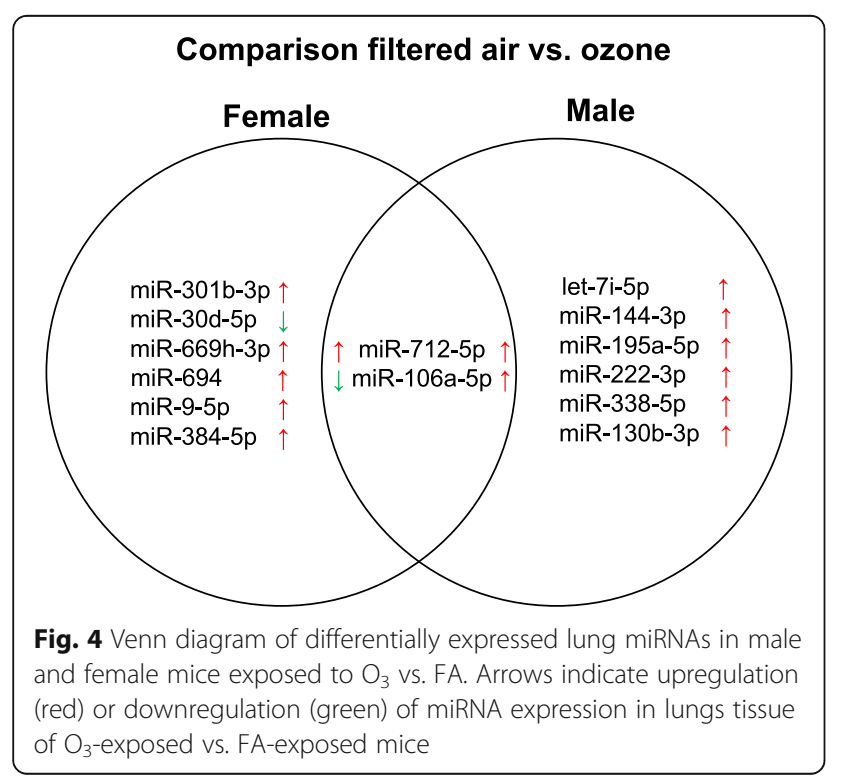

the airways when severe lung inflammation occurs [5052]. In contrast, in females exposed to $\mathrm{O}_{3}$ in the metestrus (diestrus 1), estrus, and diestrus 2 stages combined, only two miRNAs were found affected (downregulated): miR$23 \mathrm{~b}-3 \mathrm{p}$ (log fold change $=-0.330)$, and miR-30c-5p (log fold change $=-0.328$ ) (Fig. 8). The main molecular functions associated with these were cellular development, cellular compromise, and cell cycle, but also inflammatory disease (Table 4). Curiously, the tumor suppressor TP53 and TMED7, a protein involved in TLR mediated responses, were present in the molecular analysis, suggesting a correlation with the regulation of miR-23b-3p and miR-30c-5p as well as important mediators of lung immunity such as members of the TNF family (Fig. 9).

Table 3 Serum levels of luteinizing hormone (LH), estradiol (E2), and progesterone (P4) at the time of sample collection (6:00 pm) in female mice at different stages of the estrous cycle

\begin{tabular}{|c|c|c|c|c|c|c|}
\hline & \multicolumn{2}{|c|}{$\mathrm{LH}(\mathrm{mlU} / \mathrm{mL})$} & \multicolumn{2}{|c|}{ E2 $(p g / m L)$} & \multicolumn{2}{|c|}{ P4 (ng/mL) } \\
\hline & Mean & SEM & Mean & SEM & Mean & SEM \\
\hline Metestrus & 5.66 & 0.19 & 3.77 & 0.35 & 1.99 & 0.20 \\
\hline Diestrus & 4.96 & 0.33 & 2.59 & 0.38 & 5.89 & 1.84 \\
\hline Proestrus & $9.78^{*}$ & 0.43 & $7.75^{*}$ & 0.55 & 4.08 & 0.67 \\
\hline Estrus & 5.79 & 0.44 & 3.74 & 0.39 & 2.49 & 0.37 \\
\hline
\end{tabular}

*Significant difference vs. all other stages, $P<0.0001$ 
Table 4 IPA summary of females exposed to ozone in the non-proestrus and proestrus stages

\begin{tabular}{|c|c|c|c|}
\hline \multirow{2}{*}{\multicolumn{2}{|c|}{$\begin{array}{l}\text { Non-proestrus } \\
\text { A. Genes targeted by differentially expressed miRNAs }\end{array}$}} & \multicolumn{2}{|l|}{ Proestrus } \\
\hline & & & \\
\hline $\begin{array}{l}\text { CAMK2N1 } \\
\text { CARS } \\
\text { CYP24A1 } \\
\text { DBF4 } \\
\text { HMGN2 } \\
\text { KMT5A } \\
\text { LRRC17 } \\
\text { MDH2 } \\
\text { MIS18A }\end{array}$ & $\begin{array}{l}\text { SEC23A } \\
\text { SNX5 } \\
\text { SYT4 } \\
\text { THAP12 } \\
\text { TMED7 } \\
\text { TNFAIP2 } \\
\text { TNFRSF10C } \\
\text { TP53 } \\
\text { UBE2V2 } \\
\text { ZNF420 }\end{array}$ & $\begin{array}{l}\text { ABCB9 } \\
\text { APOO } \\
\text { ARHGEF38 } \\
\text { AVEN } \\
\text { CASP3 } \\
\text { CCNJ } \\
\text { CMTR2 } \\
\text { CNMD } \\
\text { DSCR8 }\end{array}$ & $\begin{array}{l}\text { SLC25A27 } \\
\text { SLC38A1 } \\
\text { TMCC1 } \\
\text { TRIM71 } \\
\text { XKR8 } \\
\text { ZCCHC11 } \\
\text { ZIM3 } \\
\text { ZNF181 }\end{array}$ \\
\hline \multicolumn{4}{|l|}{ B. Differences in top diseases and biofunctions } \\
\hline Diseases and disorders & $P$ value & Diseases and disorders & $P$ value \\
\hline Inflammatory disease & $3.84 \mathrm{E}-02$ to $3.84 \mathrm{E}-05$ & Organismal injury and abnormalities & 4.96E-02 to $2.77 \mathrm{E}-14$ \\
\hline Inflammatory response & $3.84 \mathrm{E}-02$ to $3.84 \mathrm{E}-05$ & Reproductive system disease & $2.15 \mathrm{E}-02$ to $2.77 \mathrm{E}-14$ \\
\hline Organismal injury and abnormalities & 4.17E-02 to $4.17 \mathrm{E}-05$ & Cancer & 4.96E-02 to $1.27 \mathrm{E}-10$ \\
\hline \multicolumn{4}{|l|}{ C. Top molecular and cellular functions } \\
\hline Molecular and cellular Functions & $P$ value & Molecular and cellular functions & $P$ value \\
\hline Cellular development & $2.05 \mathrm{E}-02$ to $5.26 \mathrm{E}-07$ & Cellular movement & 3.77E-02 to $4.47 \mathrm{E}-07$ \\
\hline Cellular compromise & $3.75 \mathrm{E}-04$ to $3.75 \mathrm{E}-04$ & Cellular death and survival & $4.91 \mathrm{E}-02$ to $5.61 \mathrm{E}-06$ \\
\hline Cell cycle & $2.62 \mathrm{E}-03$ to $2.62 \mathrm{E}-03$ & Cellular development & 4.97E-02 to $1.38 \mathrm{E}-06$ \\
\hline \multicolumn{4}{|c|}{ D. Top physiological system development and function } \\
\hline Development and function & $P$ value & Development and function & $P$ value \\
\hline Organismal development & 4.17E-02 to $1.31 \mathrm{E}-03$ & Embryonic development & $3.30 \mathrm{E}-02$ to $2.12 \mathrm{E}-05$ \\
\hline Embryonic development & $1.29 \mathrm{E}-02$ to $1.29 \mathrm{E}-02$ & Connective tissue development and function & $1.79 \mathrm{E}-02$ to $6.10 \mathrm{E}-05$ \\
\hline Connective tissue development and function & $1.93 \mathrm{E}-02$ to $1.93 \mathrm{E}-02$ & Tissue morphology & $7.88 \mathrm{E}-05$ to $7.88 \mathrm{E}-05$ \\
\hline \multicolumn{4}{|l|}{ E Top associated network functions } \\
\hline Associated network functions & Score & Associated network functions & Score \\
\hline $\begin{array}{l}\text { Cellular development, inflammatory disease, } \\
\text { inflammatory response }\end{array}$ & 6 & $\begin{array}{l}\text { Organismal injury and abnormalities, } \\
\text { reproductive system disease, cancer }\end{array}$ & 19 \\
\hline
\end{tabular}

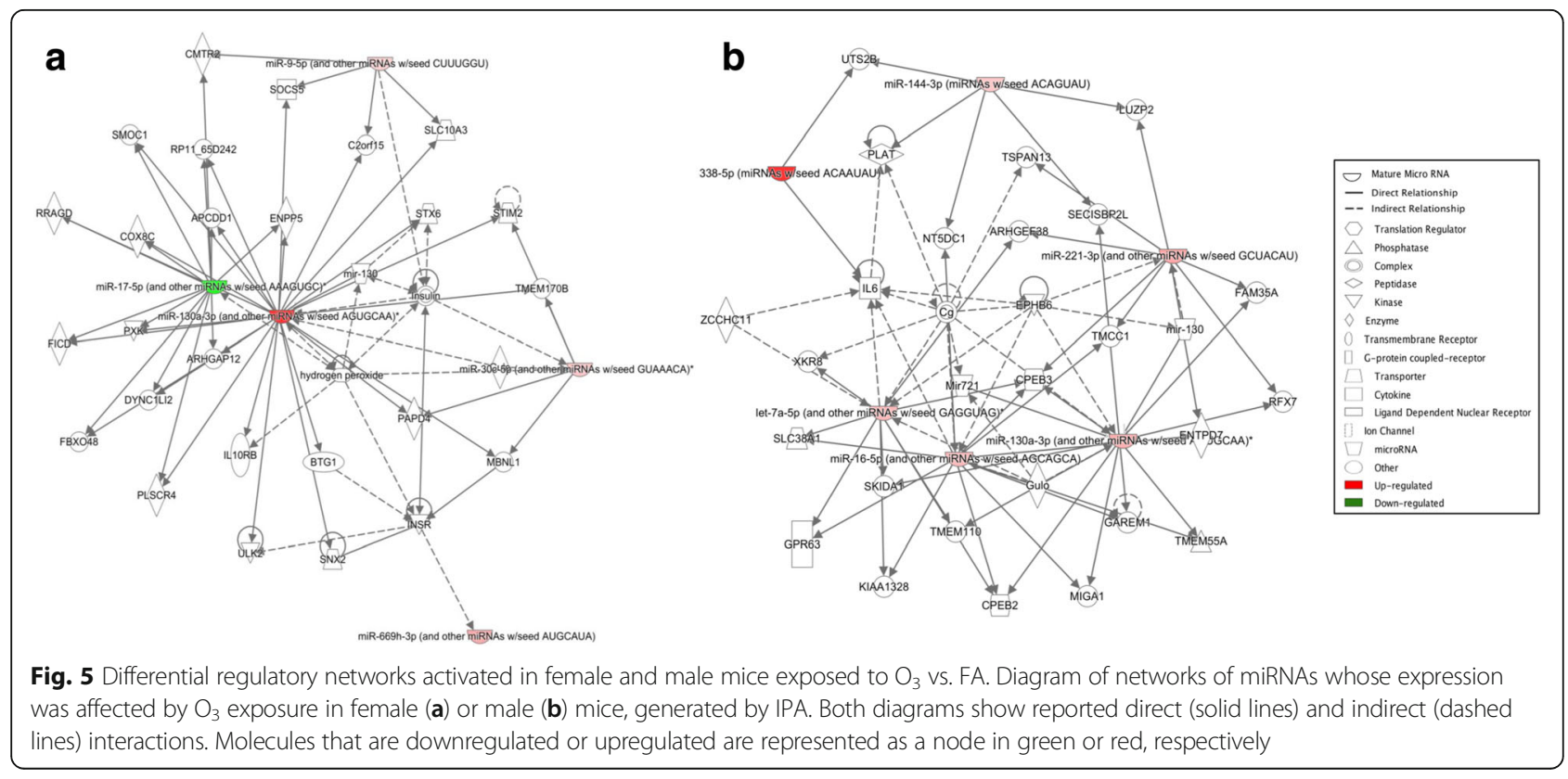



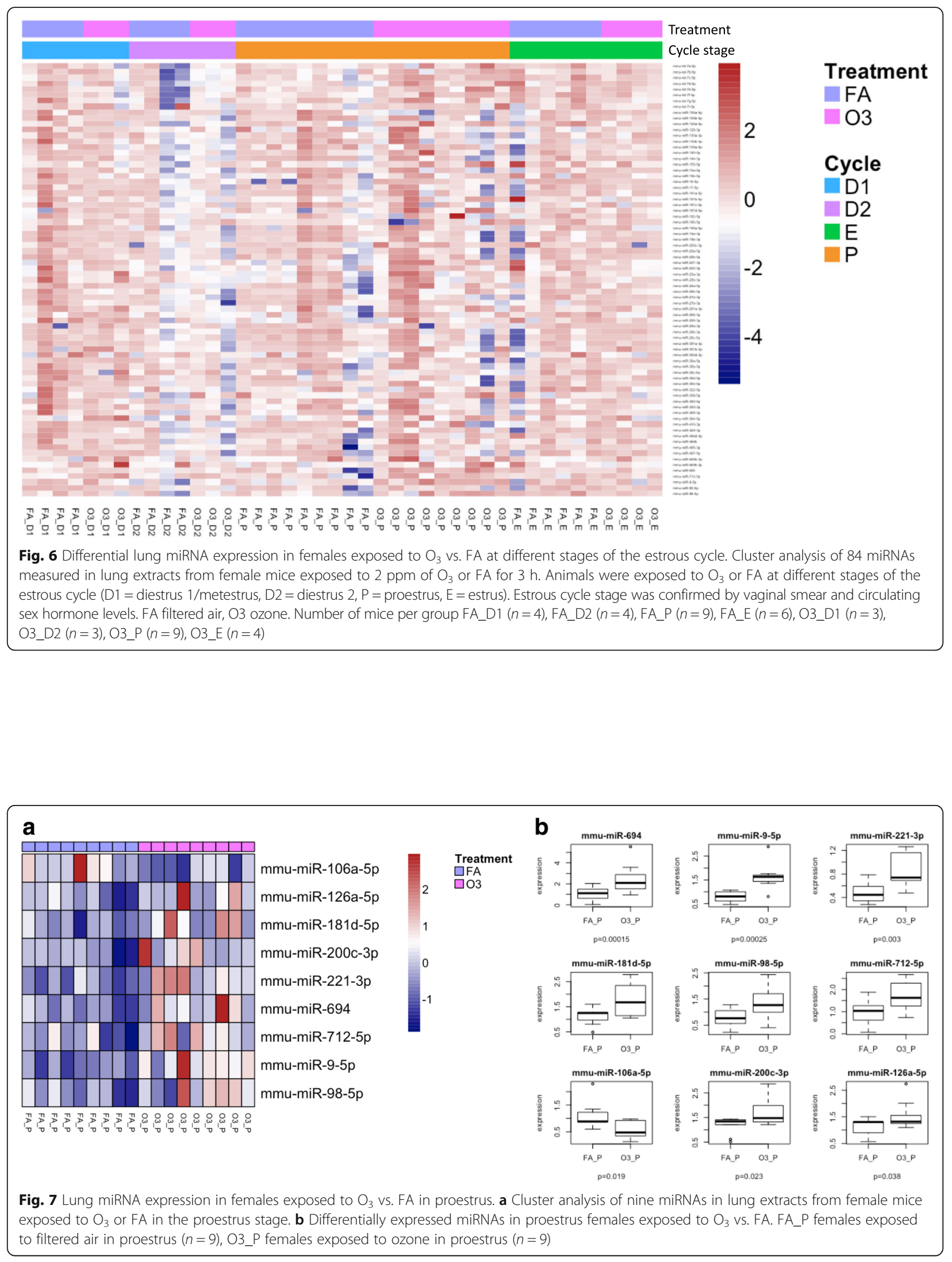


\section{a}
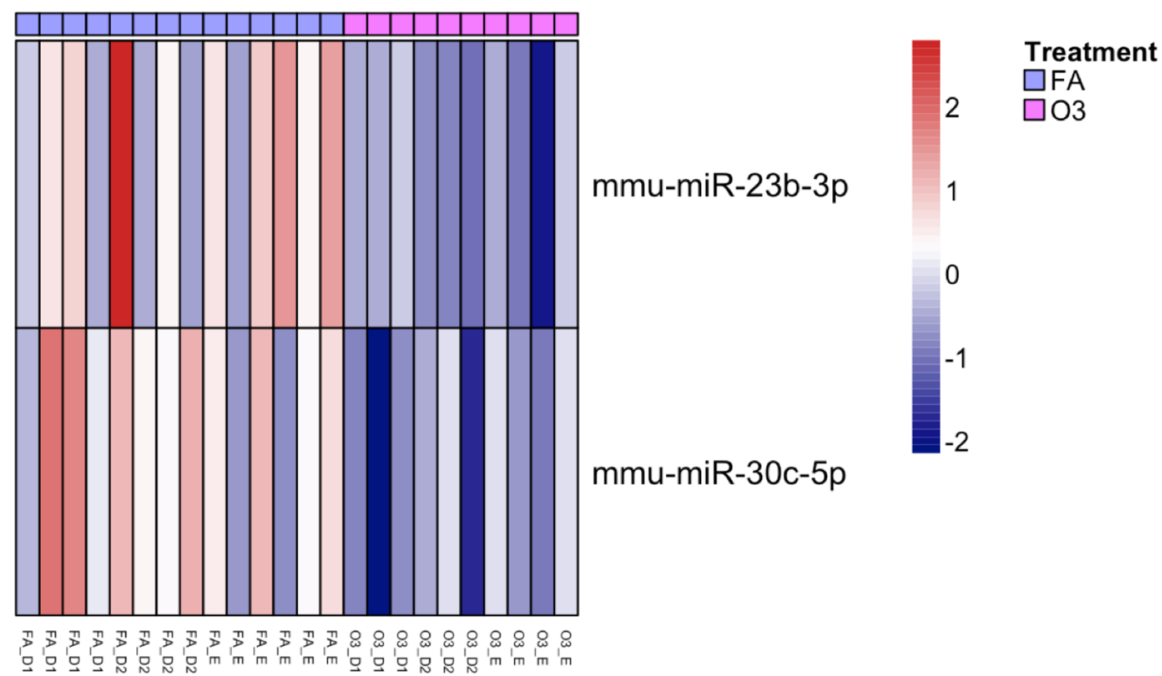

b

mmu-miR-23b-3p
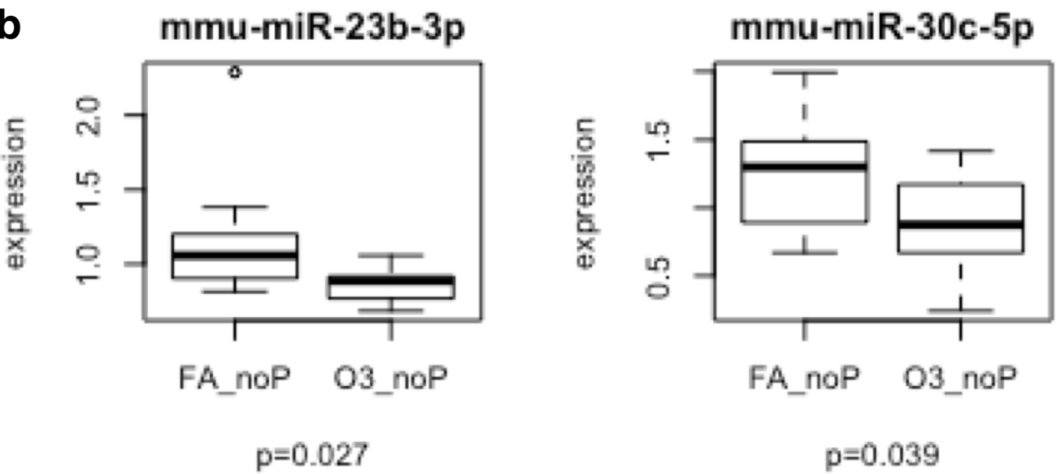

Fig. 8 Lung miRNA expression in females exposed to $\mathrm{O}_{3}$ vs. FA in non-proestrus cycle stages. a Cluster analysis of two inflammatory miRNAs in lung extracts from female mice exposed to $\mathrm{O}_{3}$ or FA in metestrus (diestrus 1), diestrus (diestrus 2), or estrus (grouped as "non-proestrus" stages). b Differentially expressed miRNAs in non-proestrus females exposed to $\mathrm{O}_{3}$ vs. FA. FA_noP females exposed to filtered air in non-proestrus stages $(n=14)$, O3_noP females exposed to ozone in non-proestrus stages $(n=10)$

\section{Discussion}

Clinical studies have reported differential outcomes for lung disease in men vs. women, as well as an increased susceptibility for women to the damaging effects of air pollution. Despite this evidence, the associated mechanisms of the pollution-induced inflammatory response in the male and female lung remain unknown. In our previous work, we reported sex-specific expression of inflammatory mediators in response to $\mathrm{O}_{3}$ exposure and a potential role of circulating hormone levels in the control of cytokine expression and associated intracellular pathways $[35,36]$. In the current study, we have further characterized sex-specific miRNA signatures in the lungs of male and female mice activated in response to $\mathrm{O}_{3}$ exposure and contributions of the estrous cycle to this regulation, since miRNAs have been previously reported as key regulators of oxidative stress responses in various tissues and diseases [53]. Our analysis using PCR arrays revealed multiple trends towards differences in miRNA expression that, although not strictly statistically significant due to lack of power, provide useful information on biological pathways affected in the male and female lung. Importantly, our results show differences in miRNA expression and differential activation of regulatory pathways in the lungs of male and female mice exposed to both FA and $\mathrm{O}_{3}$. Moreover, we found differences in the lung miRNA profiles of female mice exposed to $\mathrm{O}_{3}$ at different stages of the estrous cycle. Together, our data indicate that both sex and hormonal status can influence lung miRNA expression and, therefore, regulation of inflammatory genes, in response to $\mathrm{O}_{3}$ exposure.

The lung expresses both estrogen and progesterone receptors, and these control multiple functions of the organ $[54,55]$. Several studies, including ours, have hypothesized that female sex hormones can act as physiological modulators of lung function and immunity, via inflammatory gene expression regulation $[36,56,57]$. Evidence from clinical studies reporting menstrual cycle- 

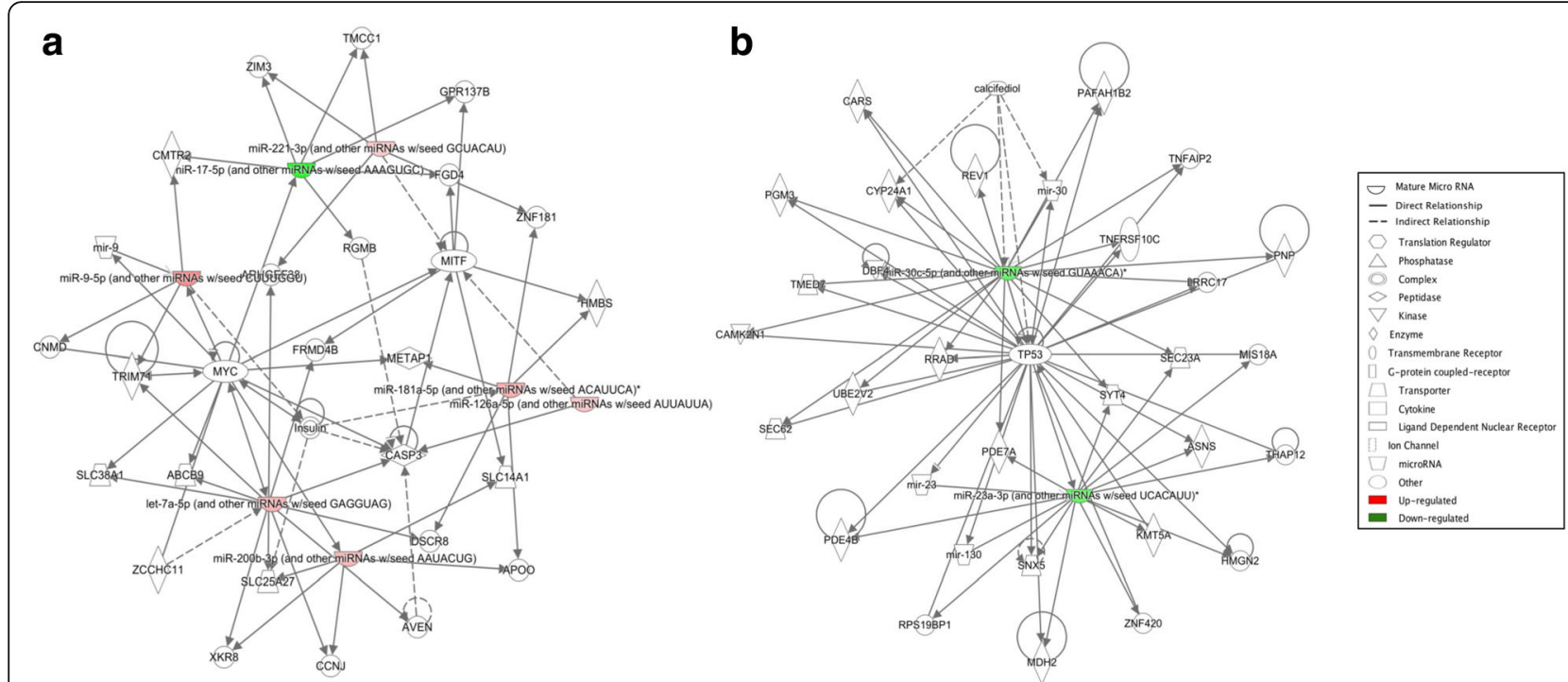

Fig. 9 Comparison of networks affected by $\mathrm{FA}_{\mathrm{A}} \mathrm{O}_{3}$ exposure in females at different stages of the estrous cycle. Diagram of biological networks associated with miRNAs whose expression was up- or downregulated in the lungs of animals exposed to $\mathrm{FA}_{\mathrm{f}}$. $\mathrm{O}_{3}$ in proestrus (a) or non-proestrus stages (b). Both diagrams show reported direct (solid lines) and indirect (dashed lines) interactions. Molecules that are downregulated or upregulated are represented as a node in green or red, respectively. Network analysis was performed with Ingenuity Pathway Analysis

dependent asthma exacerbations in women and variations in respiratory disease clinical outcomes with pregnancy and oral contraceptive use are in agreement with this hypothesis $[58,59]$. A potential mechanism by which sex hormones can effectively affect gene expression is through modulation of inflammatory gene expression by miRNAs. While other studies have explored the contributions of sex hormones to the miRNome [60], to our knowledge, this is the first study reporting sex-specific and estrous cycle day-specific miRNA profiles in response to $\mathrm{O}_{3}$ exposure. Our results also showed that the lungs of male and female mice express different miRNA profiles under basal conditions, suggesting specific roles for these miRNAs in the male and female lung.

Comparison of basal miRNA expression in males vs. females revealed two miRNAs that were differentially expressed, miR-222-3p and miR-466k. Most of the predicted gene networks affected by these miRNAs were associated with cellular growth, proliferation, and cancer. However, miR-466k is downregulated in females exposed to $\mathrm{O}_{3}$. The miR-466 family affects apoptosis regulation in mammalian cells and is a master regulator of several pathways associated with regulatory $\mathrm{T}$ cell development and function [61, 62]. In response to $\mathrm{O}_{3}$, both groups had a total of eight miRNAs that were differentially expressed. There were several similarities and differences between the groups in terms of gene networks affected. The group of miRNAs upregulated in the lungs of female mice exposed to $\mathrm{O}_{3}$ was associated with important inflammatory pathways such as the IL-10 and SOCS families. On the other hand, most miRNAs differentially expressed in male mice exposed to $\mathrm{O}_{3}$ were linked to the IL- 6 family. Together, these results suggest that $\mathrm{O}_{3}$ induces unique molecular signatures and miRNA expression profiles in the male and female lung, contributing to the previously reported sex differences in inflammatory gene expression and lung immune function.

Of particular interest is the involvement of miR-712 in the regulation of the immune response and $\mathrm{O}_{3}$-induced lung inflammation. While IPA did not associate any regulatory pathways to this miRNA, there is an apparent increase in the expression of this miRNA in females when compared to males exposed to $\mathrm{O}_{3}$. In addition, previous studies have shown that miR-712 downregulates a tissue inhibitor of metalloproteinase 3 (TIMP3), which in turn activates matrix metalloproteinases 2 and 9 (MMP2, MMP9), as well as a disintegrin and metalloproteases 10 and 17 (ADAM10, ADAM17) [40]. These metalloproteinases stimulate inflammation and, therefore, the expression of cytokines such as IL-6 and its receptor (IL6R), which according to our previous studies are highly expressed in the lungs of female mice exposed to $\mathrm{O}_{3}$ [35]. In addition, our data showed high expression of let-7i-5p in males, but not females, exposed to $\mathrm{O}_{3}$. Interestingly, this miRNA is known for inhibiting IL-6 expression, which levels are significantly higher in lung tissue from females vs. males exposed to $\mathrm{O}_{3}$ [36].

The comparison of miRNA expression in female mice exposed to FA vs. $\mathrm{O}_{3}$ revealed upregulation of both miR-9-5p and miR-130a-3p, which are known for targeting SOCS5 and altering macrophage polarization, 
respectively [63, 64]. The significance of these findings relies on the fact that these targeted molecules are involved in $\mathrm{T}$ cell differentiation and that it has been suggested that the susceptibility of female mice to $\mathrm{O}_{3}$ may be due to a Th1/Th2 imbalance [65]. Our results also showed that miR-106a-5p was upregulated in males exposed to $\mathrm{O}_{3}$ but downregulated in females exposed to $\mathrm{O}_{3}$ in the proestrus stage. It has been shown that miR106a-5p targets interleukin-10 (IL-10), an antiinflammatory cytokine that is defective in many inflammatory diseases including asthma and allergic lung inflammation [66]. Intriguingly, knockdown of this miRNA in an established allergic airway inflammation significantly alleviated most of the features of asthma such as airway hyperresponsiveness, increased Th2 response, and sub-epithelial fibrosis, along with increased IL-10 levels in the lungs of male mice [67]. However, the role of miR-106a-5p and its relationship with sex hormones and environmental pollutants remains unexplored in the female lung.

More recently, environmental factors such as $\mathrm{O}_{3}$ and airborne particulate matter have been linked to altered miRNA expression, suggesting that miRNAs may be involved in the adverse health effects of air pollution exposure [68]. Our results suggest a link between miRNAs and top diseases such as cancer and endocrine disorders. In the particular case of lung cancer, several studies have showed that certain miRNA profiles classified lung cancer subtypes and that specific miRNA expression signatures associated with lung cancer prognosis [69]. Both miR-221 (highly expressed in the proestrus stage of females exposed to $\mathrm{O}_{3}$ ) and miR-222 (upregulated in males exposed to $\mathrm{O}_{3}$ ) are involved in the development and progression of lung cancer by targeting the tumor suppressor genes PTEN and TIMP3 [70]. Moreover, overexpression of miR-221/222 is known to inhibit apoptosis and promote cell migration by downregulating PTEN and TIMP3 [71]. More importantly, miR-221/222 has been reported to target estrogen receptor alpha (ESR1), and miR-221-3p has been shown to regulate IL-6 release from abnormal airway smooth muscle in patients with severe asthma, especially women $[72,73]$. Finally, we found that miR-23b-3p was downregulated in females exposed to $\mathrm{O}_{3}$ in non-proestrus stages (i. e., when estrogen levels are low) but not in females exposed in proestrus. To this end, studies have shown that miR-23b inhibits TGF- $\beta 1$-induced airway smooth muscle proliferation and promotes apoptosis, indicating a potential role of this miRNA in lung functions and diseases that are affected by the menstrual cycle [74-77].

In summary, our studies presented here revealed sexspecific miRNA expression networks in the lungs of mice exposed to $\mathrm{O}_{3}$ or FA. Major differences involved pathways linked to the inflammatory response, endocrine diseases, respiratory function, and cancer. In addition, we identified an estrous cycle-dependent miRNA signature in females exposed to $\mathrm{O}_{3}$. Interestingly, more miRNAs were affected in females exposed to the air pollutant in the proestrus stage of the cycle (i.e., when circulating hormone levels are high) vs. the rest of the stages, indicating that sex hormones could potentially contribute to the immune response to air pollution via regulation of miRNAs. Future studies using ovariectomy and hormone replacement prior to $\mathrm{O}_{3}$ exposure could help elucidate the mechanisms behind this differential expression.

\section{Conclusion}

Using a mouse model, we found differential activation of miRNA regulatory networks in males vs. females in response to $\mathrm{O}_{3}$ exposure. Our data revealed that both sex and hormonal status can influence the lung miRNA response to $\mathrm{O}_{3}$. We also found altered expression of miRNAs that have been previously associated with IL-6 regulation in response to $\mathrm{O}_{3}$, in females and males, as well as sex differences in their expression levels. Together, these results indicate that sex-specific miRNA regulation of inflammatory gene expression could mediate differential health outcomes in men and women exposed to air pollution. This information can have significant implications for environmental health and help in the development of novel sex/gender-specific therapeutics to treat and prevent lung disease.

\section{Additional files}

\begin{abstract}
Additional file 1: Figure S1. Sex differences in inflammatory miRNA expression. A. Cluster analysis of 84 inflammatory miRNAs in lung extracts from male and female mice. B. Individual expression of miRNAs differentially expressed in lung tissue from males vs. females. M, males $(n=6)$; F females $(n=23)$. FA_M males exposed to filtered air, FA_D1 females exposed to filtered air in diestrus 1, FA_D2 females exposed to filtered air in diestrus 2, FA_P females exposed to filtered air in proestrus, FA_E females exposed to filtered air in estrus. (PDF $320 \mathrm{~kb}$ )

Additional file 2: Table S1. Target genes and associated pathways for differentially expressed miRNAs in lung tissue of unexposed male and female mice. (DOCX 23 kb)

Additional file 3: Figure S2. Sex differences in networks affected by differentially expressed miRNAs. Diagram of biological networks affected by differentially expressed miRNAs in the lungs of male and female animals exposed to $\mathrm{FA}(\mathrm{A})$ of $\mathrm{O}_{3}$ (B). Both diagrams show reported direct (solid lines) and indirect (dashed lines) interactions. Molecules that are downregulated or upregulated are represented as a node in green or red, respectively. Network analysis was performed with Ingenuity Pathway Analysis. (PDF 374 kb)
\end{abstract}

\section{Abbreviations}

ADAM10: A disintegrin and metalloproteases 10; ADAM17: A disintegrin and metalloproteases 17; COP: Chronic obstructive pulmonary disease;

D1: Diestrus 1/metestrus; D2: Diestrus; E: Estrus; FA: Filtered air; FA_D1: Females exposed to filtered air in diestrus 1; FA_D2: Females exposed to filtered air in diestrus 2; FA_E: Females exposed to filtered air in estrus; FA_M: Males exposed to filtered air; FA_noP: Females exposed to filtered air in non-proestrus stages; FA_P: Females exposed to filtered air in proestrus; FDR: Benjamini-Hochberg 
false discovery rate; IACUC: Institutional Animal Care and Use Committee; IL-10: Interleukin-10; IL-6: Interleukin-6; miRNAs: MicroRNAs; MMP2: Matrix metalloproteinases 2; MMP9: Matrix metalloproteinases 9; $\mathrm{O}_{3}$ : Ozone; O3_D1: Females exposed to ozone in diestrus 1; O3_D2: Females exposed to ozone in diestrus 2; O3_E: Females exposed to ozone in estrus; O3_M: Males exposed to ozone; O3_noP: Females exposed to ozone in non-proestrus stages; O3_P: Females exposed to ozone in proestrus; P: Proestrus; ROS: Reactive oxygen species; TIMP3: Tissue inhibitor of metalloproteinase 3

\section{Acknowledgements}

The authors thank the Pennsylvania State University College of Medicine Genome Sciences Core Facility for the Bioanalyzer analysis and real-time PCR equipment. The authors also thank Dr. Joanna Floros and Susan DiAngelo for the assistance with $\mathrm{O}_{3}$ exposure experiments.

\section{Funding}

This research was supported by grants from NIH K01HL133520 (PS) and K12HD055882 (PS)

\section{Availability of data and materials}

The datasets generated and analyzed during the current study are available in the Silveyra lab repository, available at http://psilveyra.github.io/silveyralab/ . Datasets and analyzed data have also been submitted to Gene Expression Omnibus under number GSE111667, available at https://www.ncbi.nlm.nih.gov/ geo/query/acc.cgi?acc=GSE111667.

\section{Authors' contributions}

NF, VM, and NC carried out the studies; performed the acquisition, analysis, and interpretation of data; and helped PS in drafting of the manuscript. AR assisted with the miRNA array data analysis and manuscript editing. PS designed the project, supervised the execution of experiments, performed data analysis, and prepared the manuscript. All authors read and approved the final version of the manuscript.

\section{Ethics approval and consent to participate}

This study was approved by the Pennsylvania State University College of Medicine Institutional Animal Care and Use Committee (IACUC), under protocol \#42135 "Gender Differences in Lung Disease Susceptibility in Response to Oxidative Stress: Role of miRNAs."

\section{Competing interests}

The authors declare that they have no competing interests.

\section{Publisher's Note}

Springer Nature remains neutral with regard to jurisdictional claims in published maps and institutional affiliations.

\section{Author details}

'Pulmonary, Immunology and Physiology Laboratory, Department of Pediatrics, The Pennsylvania State University College of Medicine, 500 University Drive, H085, Hershey, PA 17033, USA. ${ }^{2}$ Department of Life Sciences, Presidency University, Kolkata, India. ${ }^{3}$ Department of Biochemistry and Molecular Biology, The Pennsylvania State University College of Medicine, Hershey, PA, USA.

\section{Received: 6 January 2018 Accepted: 24 April 2018}

Published online: 08 May 2018

\section{References}

1. Brunekreef B. The continuing challenge of air pollution. Eur Respir J. 2010; 36(4):704-5.

2. Tager IB, Balmes J, Lurmann F, Ngo L, Alcorn S, Künzli N. Chronic exposure to ambient ozone and lung function in young adults. Epidemiology. 2005 16(6):751-9.

3. Fernandez R, Ariza M, Iscar M, Martinez C, Rubinos G, Gagatek S, Montoliu MA, Casan P. Impact of environmental air pollutants on disease control in asmathic patients. Lung. 2015;193(2):195-8.

4. Ciencewicki J, Trivedi S, Kleeberger SR. Oxidants and the pathogenesis of lung diseases. J Allergy Clin Immunol. 2008;122(3):456-68. quiz 469-470
5. Delfino RJ, Coate BD, Zeiger RS, Seltzer JM, Street DH, Koutrakis P. Daily asthma severity in relation to personal ozone exposure and outdoor fungal spores. Am J Respir Crit Care Med. 1996;154(3 Pt 1):633-41.

6. Sesé L, Nunes H, Cottin V, Sanyal S, Didier M, Carton Z, Israel-Biet D, Crestani B, Cadranel J, Wallaert B, et al. Role of atmospheric pollution on the natural history of idiopathic pulmonary fibrosis. Thorax. 2017;73(2):145-50.

7. Falagas ME, Mourtzoukou EG, Vardakas KZ. Sex differences in the incidence and severity of respiratory tract infections. Respir Med. 2007;101(9):1845-63.

8. Almqvist C, Worm M, Leynaert B. Impact of gender on asthma in childhood and adolescence: a GA2LEN review. Allergy. 2008;63(1):47-57.

9. de Torres JP, Cote CG, Lopez MV, Casanova C, Diaz O, Marin JM, Pinto-Plata $V$, de Oca MM, Nekach H, Dordelly $L$, et al. Sex differences in mortality in patients with COPD. Eur Respir J. 2009;33(3):528-35.

10. Varkey AB. Chronic obstructive pulmonary disease in women: exploring gender differences. Curr Opin Pulm Med. 2004;10(2):98-103.

11. Bromberg PA. Mechanisms of the acute effects of inhaled ozone in humans Biochim Biophys Acta. 2016;1860(12):2771-81.

12. Kelly FJ, Fussell JC. Air pollution and airway disease. Clin Exp Allergy. 2011; 41(8):1059-71.

13. Jerrett M, Burnett RT, Pope CA 3rd, Ito K, Thurston G, Krewski D, Shi Y, Calle E, Thun M. Long-term ozone exposure and mortality. N Engl J Med. 2009:360(11):1085-95.

14. Voter KZ, Whitin JC, Torres A, Morrow PE, Cox C, Tsai Y, Utell MJ, Frampton MW. Ozone exposure and the production of reactive oxygen species by bronchoalveolar cells in humans. Inhal Toxicol. 2001;13(6):465-83.

15. Bhatia M, Zemans RL, Jeyaseelan S. Role of chemokines in the pathogenesis of acute lung injury. Am J Respir Cell Mol Biol. 2012;46(5):566-72.

16. Yu M, Zheng $X$, Witschi $H$, Pinkerton KE. The role of interleukin-6 in pulmonary inflammation and injury induced by exposure to environmental air pollutants. Toxicol Sci. 2002;68(2):488-97.

17. Cabello N, Mishra V, Sinha U, DiAngelo SL, Chroneos ZC, Ekpa NA, Cooper TK, Caruso CR, Silveyra P. Sex differences in the expression of lung inflammatory mediators in response to ozone. Am J Physiol Lung Cell Mo Physiol. 2015;309(10):L1150-63

18. Rebane A, Akdis CA. MicroRNAs: essential players in the regulation of inflammation. J Allergy Clin Immunol. 2013;132(1):15-26.

19. Wang JX, Gao J, Ding SL, Wang K, Jiao JQ, Wang Y, Sun T, Zhou LY, Long B, Zhang XJ, et al. Oxidative modification of miR-184 enables it to target BCl-xL and Bcl-w. Mol Cell. 2015:59(1):50-61.

20. Mehta A, Baltimore D. MicroRNAs as regulatory elements in immune system logic. Nat Rev Immunol. 2016;16(5):279-94.

21. O'Connell RM, Rao DS, Chaudhuri AA, Baltimore D. Physiological and pathologica roles for microRNAs in the immune system. Nat Rev Immunol. 2010;10(2):111-22.

22. Sessa R, Hata A. Role of microRNAs in lung development and pulmonary diseases. Pulm Circ. 2013;3(2):315-28.

23. Ezzie ME, Crawford M, Cho JH, Orellana R, Zhang S, Gelinas R, Batte K, Yu L, Nuovo G, Galas D, et al. Gene expression networks in COPD: microRNA and mRNA regulation. Thorax. 2011:67(2):122-31.

24. Fanini F, Vannini I, Amadori D, Fabbri M. Clinical implications of microRNAs in lung cancer. Semin Oncol. 2011:38(6):776-80.

25. Sayed D, Abdellatif M. MicroRNAs in development and disease. Physiol Rev. 2011;91(3):827-87.

26. Harris KS, Zhang Z, McManus MT, Harfe BD, Sun X. Dicer function is essential for lung epithelium morphogenesis. Proc Natl Acad Sci U S A. 2006;103(7):2208-13.

27. Levänen B, Bhakta NR, Paredes PT, Barbeau R, Hiltbrunner S, Pollack JL, Sköld CM, Svartengren M, Grunewald J, Gabrielsson S, et al. Altered microRNA profiles in bronchoalveolar lavage fluid exosomes in asthmatic patients. J Allergy Clin Immunol. 2013;131(3):894-903.

28. Greene CM, Gaughan KP. microRNAs in asthma: potential therapeutic targets. Curr Opin Pulm Med. 2013;19(1):66-72.

29. Omran A, Elimam D, Yin F. MicroRNAs: new insights into chronic childhood diseases. Biomed Res Int. 2013;2013:291826.

30. Molina-Pinelo S, Pastor MD, Suarez R, Romero-Romero B, González De la Peña M, Salinas A, García-Carbonero R, De Miguel MJ, Rodríguez-Panadero F, Carnero A, et al. MicroRNA clusters: dysregulation in lung adenocarcinoma and COPD. Eur Respir J. 2014;43(6):1740-9.

31. Pottelberge GR, Mestdagh $P$, Bracke KR, Thas O, Durme YM, Joos GF, Vandesompele J, Brusselle GG. MicroRNA expression in induced sputum of smokers and patients with chronic obstructive pulmonary disease. Am J Respir Crit Care Med. 2011;183(7):898-906.

32. Pinkerton KE, Harbaugh M, Han MK, Jourdan Le Saux C, Van Winkle LS, Martin WJ, Kosgei RJ, Carter EJ, Sitkin N, Smiley-Jewell SM, et al. Women and 
lung disease. Sex differences and global health disparities. Am J Respir Crit Care Med. 2015;192(1):11-6.

33. Townsend EA, Miller VM, Prakash YS. Sex differences and sex steroids in lung health and disease. Endocr Rev. 2012;33(1):1-47.

34. Dai R, Ahmed SA. Sexual dimorphism of miRNA expression: a new perspective in understanding the sex bias of autoimmune diseases. The Clin Risk Manag. 2014;10:151-63.

35. Mishra V, DiAngelo SL, Silveyra P. Sex-specific IL-6-associated signaling activation in ozone-induced lung inflammation. Biol Sex Differ. 2016;7:16

36. Cabello N, Mishra V, Sinha U, DiAngelo SL, Chroneos ZC, Ekpa NA, Cooper $T K$, Caruso CR, Silveyra P. Sex differences in the expression of lung inflammatory mediators in response to ozone. Am J Physiol Lung Cell Mol Physiol. 2015; https://doi.org/10.1152/ajplung.00018.2015.

37. Mikerov AN, Hu S, Durrani F, Gan X, Wang G, Umstead TM, Phelps DS, Floros $\mathrm{J}$. Impact of sex and ozone exposure on the course of pneumonia in wild type and SP-A (-/-) mice. Microb Pathog. 2012;52(4):239-49.

38. Durrani F, Phelps DS, Weisz J, Silveyra P, Hu S, Mikerov AN, Floros J. Gonadal hormones and oxidative stress interaction differentially affects survival of male and female mice after lung Klebsiella Pneumoniae infection. Exp Lung Res. 2011;38(4):165-72

39. Wang Q, Wang Z, Chu L, Li X, Kan P, Xin X, Zhu Y, Yang P. The effects and molecular mechanisms of MiR-106a in multidrug resistance reversal in human glioma U87/DDP and U251/G cell lines. PLoS One. 2015;10(5): e0125473.

40. Son DJ, Kumar S, Takabe W, Kim CW, Ni CW, Alberts-Grill N, Jang $\mathrm{H}_{\text {, Kim S, }}$ Kim W, Won Kang S, et al. The atypical mechanosensitive microRNA-712 derived from pre-ribosomal RNA induces endothelial inflammation and atherosclerosis. Nat Commun. 2013;4:3000

41. Caligioni CS. Assessing reproductive status/stages in mice. Curr Protoc Neurosci. 2009;Appendix 4:Appendix 4l.

42. Umstead TM, Phelps DS, Wang G, Floros J, Tarkington BK. In vitro exposure of proteins to ozone. Toxicol Mech Methods. 2002;12(1):1-16.

43. Hatch GE, Koren H, Aissa M. A method for comparison of animal and human alveolar dose and toxic effect of inhaled ozone. Health Phys. 1989; 57(Suppl 1):37-40.

44. Hatch GE, Slade R, Harris LP, McDonnell WF, Devlin RB, Koren HS, Costa DL, McKee J. Ozone dose and effect in humans and rats. A comparison using oxygen-18 labeling and bronchoalveolar lavage. Am J Respir Crit Care Med. 1994;150(3):676-83.

45. Livak KJ, Schmittgen TD. Analysis of relative gene expression data using real-time quantitative PCR and the 2(-delta delta $C(T)$ ) method. Methods. 2001;25(4):402-8

46. Benjamini Y, Hochberg Y. Controlling the false discovery rate: a practical and powerful approach to multiple testing. J R Stat Soc Ser B Methodol. 1995;57(1):289-300.

47. Giefing-Kröll C, Berger P, Lepperdinger G, Grubeck-Loebenstein B. How sex and age affect immune responses, susceptibility to infections, and response to vaccination. Aging Cell. 2015;14(3):309-21.

48. Klein SL, Flanagan KL. Sex differences in immune responses. Nat Rev Immunol. 2016;16(10):626-38.

49. Silveyra P, Catalano P, Lux-Lantos V, Libertun C. Impact of proestrous milieu on expression of orexin receptors and prepro-orexin in rat hypothalamus and hypophysis: actions of Cetrorelix and Nembutal. Am J Physiol Endocrinol Metab. 2007;292(3):E820-8.

50. Hotti A, Järvinen K, Siivola P, Hölttä E. Caspases and mitochondria in C-Mycinduced apoptosis: identification of ATM as a new target of caspases. Oncogene. 2000;19(19):2354-62.

51. Chen Z, Zhang Y, Yang J, Jin M, Wang XW, Shen ZQ, Qiu Z, Zhao G, Wang J, Li JW. Estrogen promotes benzo[a]pyrene-induced lung carcinogenesis through oxidative stress damage and cytochrome c-mediated caspase-3 activation pathways in female mice. Cancer Lett. 2011;308(1):14-22.

52. Truong-Tran AQ, Grosser D, Ruffin RE, Murgia C, Zalewski PD. Apoptosis in the normal and inflamed airway epithelium: role of zinc in epithelial protection and procaspase-3 regulation. Biochem Pharmacol. 2003;66(8):1459-68.

53. Banerjee J, Khanna S, Bhattacharya A. MicroRNA regulation of oxidative stress. Oxidative Med Cell Longev. 2017;2017:2872156.

54. Massaro D, Clerch LB, Massaro GD. Estrogen receptor-alpha regulates pulmonary alveolar loss and regeneration in female mice: morphometric and gene expression studies. Am J Physiol Lung Cell Mol Physiol. 2007;293(1):L222-8.

55. Gilliver SC. Sex steroids as inflammatory regulators. J Steroid Biochem Mol Biol. 2010;120(2-3):105-15.
56. Tam A, Morrish D, Wadsworth S, Dorscheid D, Man SF, Sin DD. The role of female hormones on lung function in chronic lung diseases. BMC Womens Health. 2011;11:24.

57. Card JW, Zeldin DC. Hormonal influences on lung function and response to environmental agents: lessons from animal models of respiratory disease. Proc Am Thorac Soc. 2009;6(7):588-95.

58. Hanley SP. Asthma variation with menstruation. Br J Dis Chest. 1981;75(3):306-8.

59. Pauli BD, Reid RL, Munt PW, Wigle RD, Forkert L. Influence of the menstrual cycle on airway function in asthmatic and normal subjects. Am Rev Respir Dis. 1989;140(2):358-62.

60. Klinge CM. Estrogen regulation of microRNA expression. Curr Genomics. 2009;10(3):169-83.

61. Druz A, Chu C, Majors B, Santuary R, Betenbaugh M, Shiloach J. A novel microRNA mmu-miR-466h affects apoptosis regulation in mammalian cells. Biotechnol Bioeng. 2011;108(7):1651-61.

62. Okoye IS, Coomes SM, Pelly VS, Czieso S, Papayannopoulos V, Tolmachova T, Seabra MC, Wilson MS. MicroRNA-containing T-regulatory-cell-derived exosomes suppress pathogenic T helper 1 cells. Immunity. 2014;41(1):89-103.

63. Seashols-Williams SJ, Budd W, Clark GC, Wu Q, Daniel R, Dragoescu E, Zehner ZE. miR-9 acts as an oncomiR in prostate cancer through multiple pathways that drive tumour progression and metastasis. PLoS One. 2016;11(7):e0159601.

64. Lin L, Lin H, Wang L, Wang B, Hao X, Shi Y. miR-130a regulates macrophage polarization and is associated with non-small cell lung cancer. Oncol Rep. 2015;34(6):3088-96.

65. Yoshimura A, Naka T, Kubo M. SOCS proteins, cytokine signalling and immune regulation. Nat Rev Immunol. 2007;7(6):454-65.

66. Sharma A, Kumar M, Aich J, Hariharan M, Brahmachari SK, Agrawal A, Ghosh B. Posttranscriptional regulation of interleukin-10 expression by hsa-miR106a. Proc Natl Acad Sci U S A. 2009;106(14):5761-6.

67. Sharma A, Kumar M, Ahmad T, Mabalirajan U, Aich J, Agrawal A, Ghosh B, Antagonism of mmu-mir-106a attenuates asthma features in allergic murine model. J Appl Physiol (1985). 2012;113(3):459-64.

68. Sonkoly E, Pivarcsi A. MicroRNAs in inflammation and response to injuries induced by environmental pollution. Mutat Res. 2011;717(1-2):46-53.

69. Nana-Sinkam SP, Croce CM. Clinical applications for microRNAs in cancer. Clin Pharmacol Ther. 2013;93(1):98-104.

70. Inamura K, Ishikawa Y. MicroRNA in lung cancer: novel biomarkers and potential tools for treatment. Ochiya T, Takahashi R, eds. J Clin Med. 2016; 5(3):36.

71. Garofalo M, Di Leva G, Romano G, Nuovo G, Suh SS, Ngankeu A, Taccioli C, Pichiorri F, Alder H, Secchiero P, et al. miR-221\&222 regulate TRAIL resistance and enhance tumorigenicity through PTEN and TIMP3 downregulation. Cancer Cell. 2009;16(6):498-509.

72. Cochrane DR, Cittelly DM, Howe EN, Spoelstra NS, McKinsey EL, LaPara K, Elias A, Yee D, Richer JK. MicroRNAs link estrogen receptor alpha status and Dicer levels in breast cancer. Horm Cancer. 2010;1(6):306-19.

73. Perry MM, Baker JE, Gibeon DS, Adcock IM, Chung KF. Airway smooth muscle hyperproliferation is regulated by microRNA-221 in severe asthma. Am J Respir Cell Mol Biol. 2014;50(1):7-17.

74. Chen M, Huang L, Zhang W, Shi J, Lin X, Lv Z, Liang R, Jiang S. MiR-23b controls TGF- $\beta 1$ induced airway smooth muscle cell proliferation via TGFBR2/p-Smad3 signals. Mol Immunol. 2016;70:84-93.

75. Farha S, Asosingh K, Laskowski D, Hammel J, Dweik RA, Wiedemann HP, Erzurum SC. Effects of the menstrual cycle on lung function variables in women with asthma. Am J Respir Crit Care Med. 2009;180(4):304-10.

76. Tan KS, McFarlane LC, Lipworth BJ. Loss of normal cyclical beta 2 adrenoceptor regulation and increased premenstrual responsiveness to adenosine monophosphate in stable female asthmatic patients. Thorax. 1997;52(7):608-11.

77. Wheeldon NM, Newnham DM, Coutie WJ, Peters JA, McDevitt DG, Lipworth BJ. Influence of sex-steroid hormones on the regulation of lymphocyte beta 2adrenoceptors during the menstrual cycle. Br J Clin Pharmacol. 1994;37(6):583-8. 